\title{
THE RUTGERS COLLECTION OF CHILDREN'S LITERATURE
}

\section{BY DOROTHY VERKERK}

Ms. Verkerk was formerly Coordinator of the Children's Literature Collection and is a doctoral candidate in the Rutgers Department of Art History

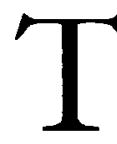

HE RUTGERS Collection of Children's Literature is a repository for the original art of children's books and contains over 3,000 pieces of artwork spanning fifty years of American book illustration. The collection is housed at the Jane Voorhees Zimmerli Art Museum, Rutgers, the State University of New Jersey. Although the emphasis is on New Jersey illustrators, the collection represents artists from all over the country who have generously donated their artwork. The collection is dedicated to furthering scholarly research and artistic creativity by documenting the production of children's books from the preparatory sketches to the full-color illustrations and the finished book. Original manuscripts are also collected and preserved by the Special Collections Department at the Archibald S. Alexander Library, the main library center for the university. By gathering together the written and visual material of children's books, the collection provides an invaluable archive for future research on this important genre.

The director of the art museum, Phillip Dennis Cate, first became interested in the art for children's books in I 974 when he organized the exhibition "American Illustrators of Children's Books." The quality of the artwork in that exhibition inspired the university to respond to the growing interest in establishing an archive for manuscripts and illustrations of children's books. Harry Devlin, a prominent illustrator and member of the Advisory Council on Children's Literature, was the prime mover behind the concept of the repository. It was his concern that a wealth of artwork by New Jersey artists was leaving the state and being collected by other institutions. 'The collection was officially founded in I 979 and was quickly expanded to encompass artists from all parts of the United States, Europe, and Asia.

A collection of the original art for the printed book complements the art

${ }^{1}$ James H. Fraser, Children's Authors and Illustrators: A Guide to Manuscript Collections in the United States Research Libraries (New York, Munich, London, Paris: K.G. Saur Publishing Inc., Phaedrus Bibliographic Series No. I). 
museum's overall interest in the graphic arts and its technical history. The primary focus of the art museum is its extensive collection of nineteenthand twentieth-century French and American prints. As indicated, the art museum not only collects works on paper but also emphasizes the various technical processes involved in modern printmaking. ${ }^{2}$ Another unique facet of the art museum is the Archives for Printmaking Studios, a collection which documents technical innovations and preparatory aspects of contemporary printmaking rather than the oeuvre of an individual artist or artistic movement. Within this context, the Rutgers Collection of Children's Literature is particularly appropriate since the archive is comprised of the various types of artwork produced in the long and involved process of creating a child's book.

An exceptional picture book is the result of both spontaneity and careful planning. One of the most important tools for planning a book is the

${ }^{2}$ Phillip Dennis Cate, "Printing in France, I 850-1 900: The Artist and New Technologies," Gazette of the Grolier Club, Numbers 28-29, June-December, 1978, 57-73.

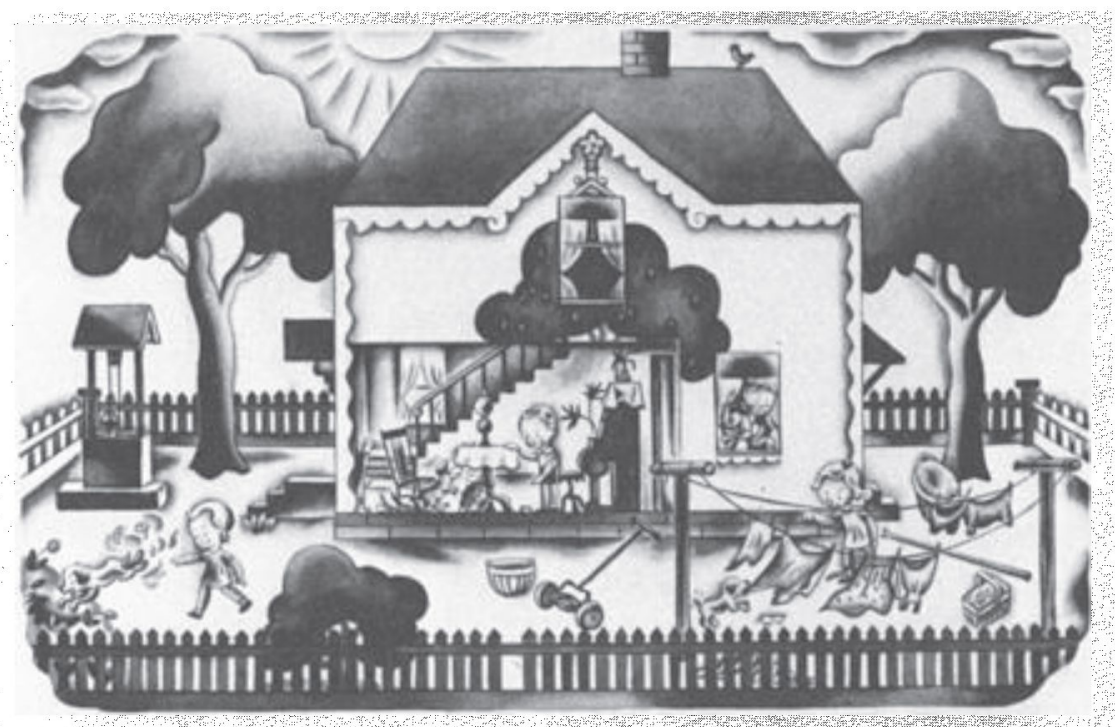

SUGARPLUM HOUSE

Written and illustrated by Lois Lenski, I 935.

Pen and ink, ink wash

Jane Voorhees Zimmerli Art Museum

Rutgers, The State University of New Jersey 
dummy, a preliminary model of the book. The dummy conveys how the book will read, visually and syntactically, when printed. Turning the pages allows the illustrator to experience the progression and the pages' relation to each other. ${ }^{3}$ The dummy is the most helpful tool in communicating to the editor or book designer the artist's concept for the book. Preserving the dummy, or dummies, is also an invaluable aid for the researcher to follow the development of the artist's thought.

Once the artist feels the dummy has reached its final form, the next step is to make a color study, which is a painting of the illustration in the colors chosen by the artist. This color study serves as a guide in preparing the complicated process of color separation. ${ }^{4}$ This is the technique of separating the color originals into the primary printing color componentsblack, red, blue, and yellow. This can be done mechanically by camera or computer, or it can be done manually by the artist, a process frequently referred to as preseparation. The advantages of manual color separation are both economical - four-color printing is very expensive-and artistic. An artist who is a master of color separation can achieve certain subtleties in the richness or sharpness of texture and tone that the camera or computor cannot reproduce. ${ }^{5}$

In color separation, the artist separates the color by preparing a keyplate and one or more overlays, depending on the number of colors the artist and publisher have agreed upon. A keyplate, usually the color black, is the master separation, which contains most of the image and is thus more readable than the overlays of the same picture. Although the keyplate and overlays are usually painted in blacks or grays, each represents the different tones of a color specified by the artist. The artist prepares all the blue, yellow, and red tones on separate sheets of paper or acetate. The printer follows these instructions so that each keyplate or overlay is reproduced as a one-color image. When printed together, they form a multicolor picture.

Since a full-color image is nearly always reproduced using only four colors, the printed form can never exactly replicate the original illustration. Within the limits of technology, the printed book is actually an interpretation of the artist's original concept. Although the printed book ena-

${ }^{3}$ Uri Shulevitz, Writing with Pictures: How to Write and Illustrate Children's Books (New York: Watson-Guptill Publications, I 985), 79-80.

4 For more detailed information on color separation see Shulevitz, Writing with Pictures, 2 I4-24I, which provides one of the most lucid and instructive information designed especially for the artist; see also Adrienne Adams, "Color Separation," in The Illustrator's Notebook, edited by Lee Kingman (Boston: The Horn Book, Incorporated, 1978), 97-103.

${ }^{5}$ Shulevitz, Writing with Pictures, 2 I 4. 
bles the artist's work to reach a far greater number of people, the spontaneity and vibrancy of the original art can never be duplicated in the printing process. Each artist chooses and manipulates the medium in order to achieve the best reproduction possible. All of the various stages of illustration, therefore, are important to preserve in order to document the artist's concept for a book and the individual manner of working.

Children's literature has often been relegated by uninformed adults to an inferior position in critical or historical surveys of world literature. Even for the layman, children's books are "kids' stuff." Roger Duvoisin has humorously summed up the attitude writers and artists frequently encounter:

What standing have they [writers and illustrators] won in our society? Who will take seriously artists who spend so much of their time playing with children and children's books? Not many people in my own experience. When I filled out an application for a passport last year, I wrote "Children's book illustrator and writer" in the space for "occupation." When the clerk saw this he looked up with a wink and a smile and said, "Hm, children's books, eh?" There was absolutely no doubt that he meant, "Hm, harmless fellow." Or at a party of serious business people, a lady friend is liable to introduce you to a grave-looking gentleman and say, "This is Roger Duvoisin; he is the author of Petunia the Silly Goose." This is sure to bring another wink and a smile. ${ }^{6}$

Many authors have lamented this bias and have strived to correct the status of their genre.? With the art for children's books, however, the adult chauvinism and the lack of critical study is even more pronounced. Writers of children's books enjoy a certain amount of critical appraisal in the field of literature due to the laudable efforts of teachers, writers, and librarians; however, illustrators are commonly overlooked in any critical review of a children's book. ${ }^{8}$ One of the primary factors in this deplorable oversight is that children's literature has been traditionally the domain of editors, librarians, and teachers who are rarely trained in the visual arts.

${ }^{6}$ Roger Duvoisin, "Children's book illustration: the pleasures and problems," in Only Connect: Readings on Children's Literature, edited by Sheila Egoff, G. T. Stubbs, and L. F. Ashley (Toronto, New York: Oxford University Press, 1980, second edition), 30I-303.

7 Roger Lancelyn Green, "The golden age of children's books," in Only Connect, I-I6; see also a compilation of important articles in "Status: In and Out of the Literary Sandbox," reprinted in Signposts to Criticism of Children's Literature, edited by Robert Bator (Chicago: American Library Association, I 983), 2 I-65.

${ }^{8}$ Kenneth Marantz, "The Picture Book as Art Object: A Call for Balanced Reviewing," reprinted in Signposts, I $52-$ I 55. 


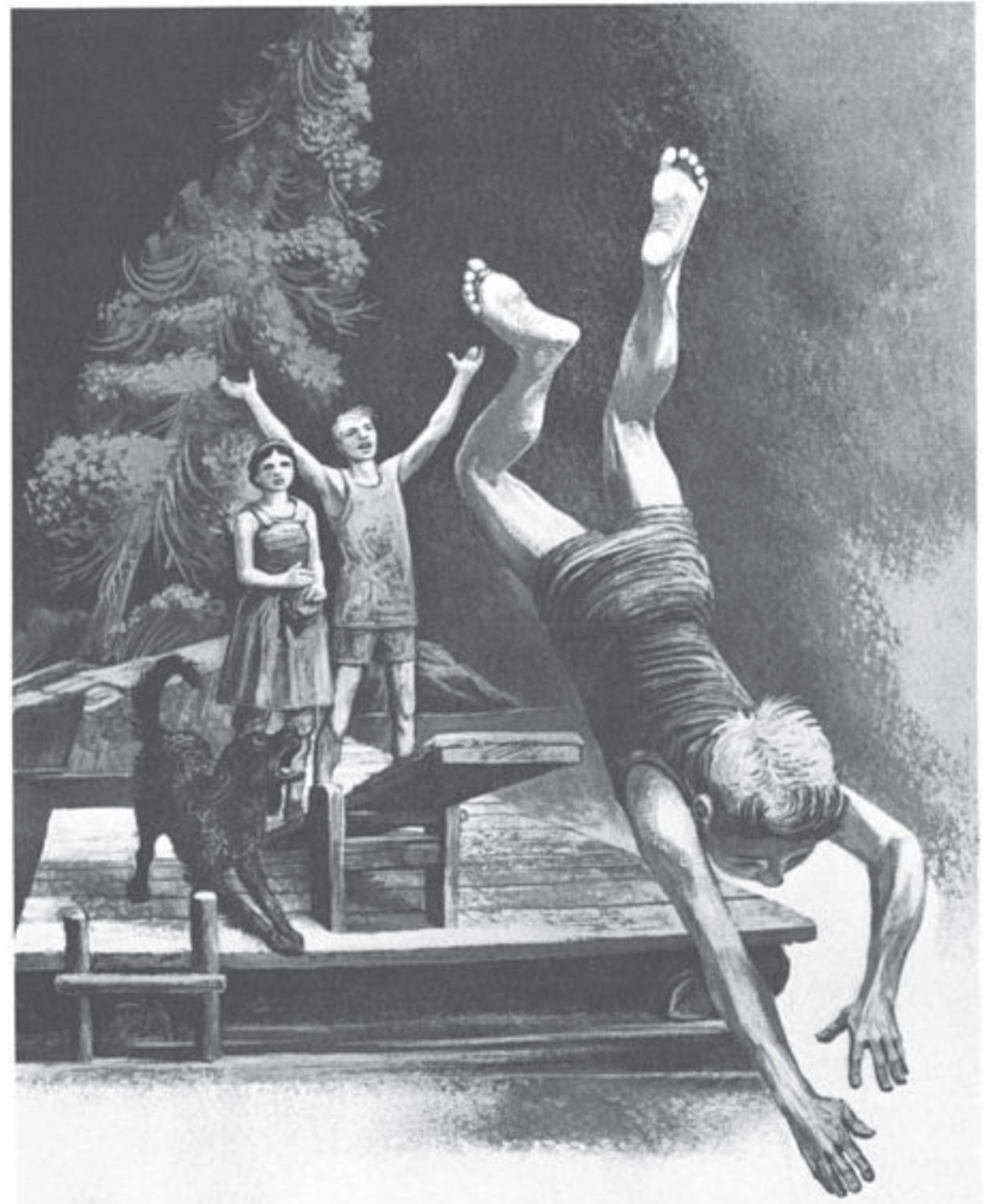

NIC OF THE WOODS

Written and illustrated by Lynd Ward, I965. Casein.

Jane Voorhees Zimmerli Art Museum

Rutgers, The State University of New Jersey 
Some experts in children's literature criticize the illustrators for being more concerned with artistic innovations than with pleasing the tastes and understanding of a child. 9 Yet no one has been able to define or identify adequately what artistic forms children can or cannot understand or appreciate. Unlike literature, art does not have a vocabulary level that prohibits appreciation. This is especially interesting since many artists will write their own books but rarely does the author take up the drawing pen or painting brush. There is a real need for the art of children's books to be given the status it deserves in an art museum where it can be studied and exhibited in an environment which nurtures and critiques the visual arts.

The art for children's books, however, is different from many other forms of art. It does not stand alone in the ivory tower isolation enjoyed by many of the so-called high or fine arts. The illustration is an integral part of the text which it illuminates or informs. Artists have written extensively on what constitutes successful illustration in a picture book. ${ }^{\text {ro }}$ One of the most succinct descriptions of the illustration's role is given by the artist Edward Ardizzone:

. . the text can only give bones to the story. The pictures on the other hand, must do more than just illustrate the story. They must elaborate it. Characters have to be created pictorially because there is no space to do so verbally in the text. Besides the settings and characters, the subtleties of mood and moment have to be suggested. ${ }^{\text {I }}$

Illustration in picture books is the artist's interpretation of the narrative using a pictorial rather than a verbal language. The role of the children's book illustration is very similar to that of the frescoes in medieval churches which were designed to tell the illiterate a story that had already been verbally transmitted to them, thus using pictures to reinforce the content of the narrative. ${ }^{12}$

Like the medieval fresco, the illustrations and the stories are indicators of the values and ideals of the society that produces them. Adults are concerned, perhaps overly concerned, with the books given to their children. ${ }^{13}$ The amount of ink spilled on what is appropriate for children's

9 Barbara Bader, "Picture Books, Art and Illustration," in Newbery and Caldecott Medal Books: 1966-1975, edited by Lee Kingman (Boston: The Horn Book, Incorporated, 1975).

10 Uri Shulevitz, "What is a Picture Book?" Wilson Library Bulletin, 55, I 980, 1ooff; see also Marcia Brown, Lotus Seeds: Children, Pictures, and Books (New York: Charles Scribner's Sons, I986).

"Edward Ardizzone, "Creation of a Picture Book," in Only connect, 290.

12 Roger Duvoisin, Only Connect, 305.

1.3 Constantine Georgiou, Children and Their Literature (Englewood Cliffs, NJ: PrenticeHall, Inc., I 969), 3-4.3. 
illustration far exceeds that used in creating the art. Thus, for the art historian and the cultural historian children's books can provide a surprisingly accurate barometer of a society's concerns and even its foibles.

In the art museum, the curator is able to display an entire set of illustrations with the text, providing a unique opportunity for the contemplation of the original art. Frequently, when the original art for children's books is on exhibition, the illustrations are displayed one at a time without the text. The artwork has then ceased to function in its intended role and has become merely a painting or drawing displayed in isolation on a wall. This is not necessarily objectionable, since good illustration must be able to stand on its own as a work of art. One loses, however, the sense of the illustration as part of a complete work of art, with each page complementing the others and amplifying the text. The artist has conceived the illustrations as a whole and has created them to work together as a seamless unit. By isolating the individual pictures, the original conception is lost. A collection of the original art for children's books, therefore, allows the casual visitor, the connoisseur, and the fellow artist the ability to study the illustrations in their proper context.

Perhaps one of the most important reasons to collect the original art for children's books is that picture books are often the first exposure one has to art. For some, unfortunately, the picture books of childhood will be the only real interaction they will have with fine art. The paintings and drawings of a child's book often form the basis for future appreciation and understanding of the artistic world. ${ }^{14}$ Furthermore, the illustrations in the books from one's childhood are the shared images which bind a generation together. For me, Adrienne Adams' beautiful watercolors for Hans Christian Andersen's The Ugly Duckling were a delight to discover in the collection, since I recalled reading and rereading the fairytale and finding constant enjoyment in the pictures. When describing my experience to a friend, she too remembered with pleasure the images and was able to describe them in detail. This is a common experience, as one only has to mention the Cat in the Hat or Curious George to immediately elicit a response from one's peers. Not only are these images a common bond between one generation, but they are also a heritage to be passed on to future generations of children and the artists those generations will produce.

The first generation of artists in the Rutgers collection began their careers in the late twenties, thirties, and early forties. After World War II, technological and social developments, in conjunction with a rising birth

${ }^{14}$ Ibid., 63. 


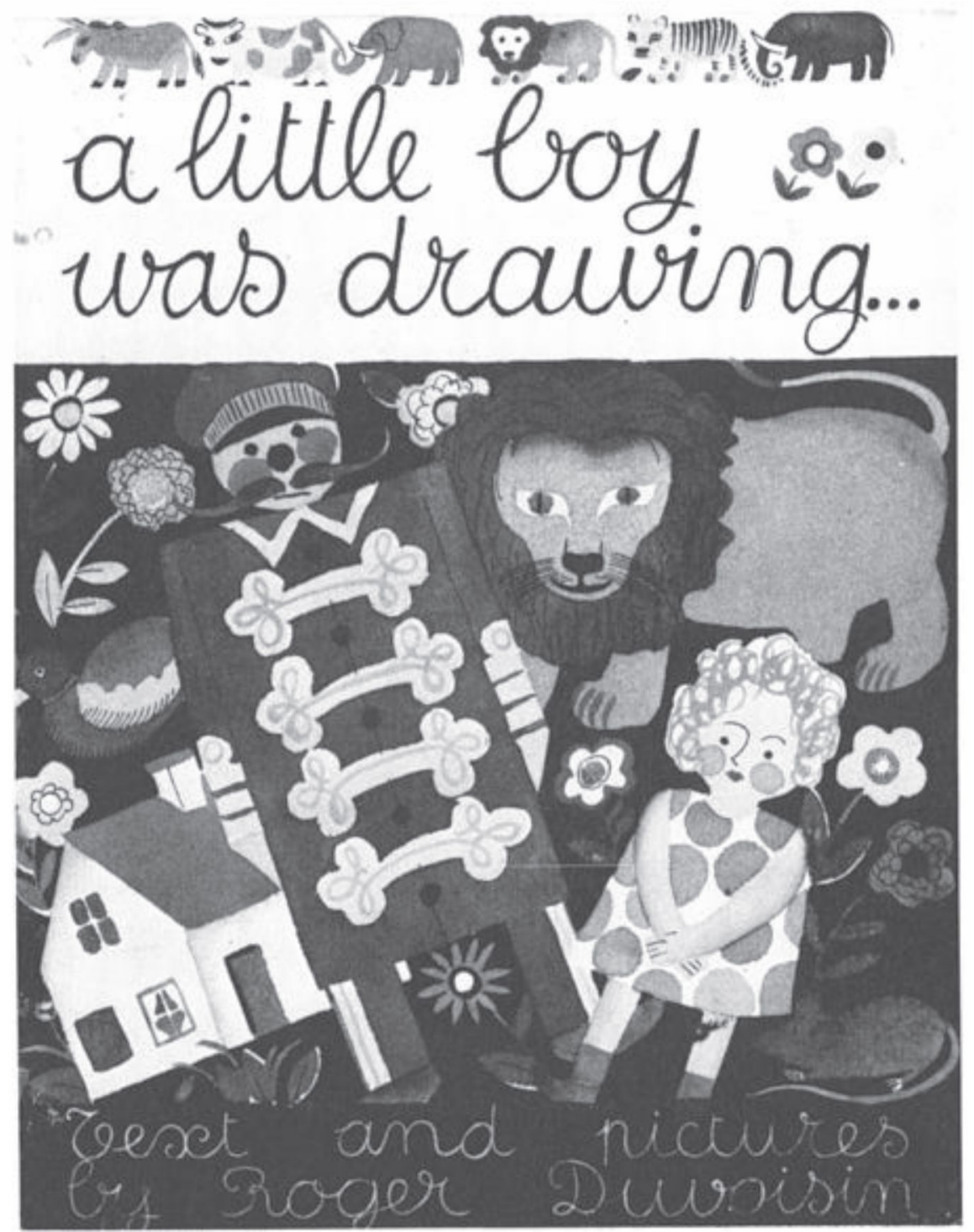

A LITTLE BOY WAS DRAWING

Written and illustrated by Roger Duvoisin, I 932.

Gouache, pen and ink

Jane Voorhees Zimmerli Art Museum

Rutgers, The State University of New Jersey 
rate, contributed to a new interest in the influence of visual stimuli on a child's development. The result was an explosion in the publication of picture books. At the same time, advancements in photo-mechanical reproduction and the opportunity to experiment with diverse media and innovative forms of expression encouraged a greater number of artists to turn to picture book illustration. Many of the artists preferred to work in children's book illustration because of the artistic freedom it offered and the opportunity to express visually the values they believed important to pass on to children.

Artists such as Adrienne Adams, Barbara Cooney, Roger Duvoisin, Lois Lenski, and Lynd Ward laid a firm foundation of technical expertise, in addition to aesthetic integrity - honesty in presentation, imagination, humor-which distinguished children's picture book illustration in the United States. One of the most distinguishing features of their artwork is the constant growth and change in their artistic oeuvres. Some of the illustrators, such as Barbara Cooney, have developed several styles which they adapt to the needs of the story line. Cooney's award-winning illustrations for Ox-Cart Man were inspired by American folk art because the artist felt it was the most appropriate style for the story about a nineteenth-century New England family. Roger Duvoisin's oeuvre frequently changed over a long period of time as he began to experiment with many different styles and media. Although he is most well known for his line drawings and color washes, Duvoisin began his career using flat areas of color defined by a thick black line; much like the drawing of a young child. In his later career, Duvoisin changed his medium to collage using paint-splattered, cut paper to create a highly textural effect which easily translated into print. These illustrators were also cognizant of the art movements which were taking place outside the realm of children's books. In the work of Lois Lenski the influence of the American Regionalist movement of the I 93 Os can be clearly seen in her emphasis on bold contours, simplification of forms, and narrative clarity. Lynd Ward was a prolific artist who established his reputation in the graphic arts and was heavily involved in artistic movements such as the American Artist's Congress. Lynd Ward was also influential for his essays on the need for higher artistic and philosophical standards in children's literature. ${ }^{\text {is }}$

The new generation of artists has profited not only from the foundation laid down by earlier illustrators but also from further advances in photomechanical reproduction which allow greater innovation in the choice of

is Lynd Ward, "Contemporary Book Illustration," in Illustrator's Notebook, 5-7; originally published in The Horn Book Magazine, 1930. 
color and media. To create their own distinctive styles, children's book illustrators continue to find inspiration from the works of other illustrators and artistic movements. Erik Blegvad's detailed pen and ink drawings for The Three Little Pigs, for example, recall the artwork of Beatrix Potter. Fuku Akino's watercolor illustrations recapture the expression and conventions of the Japanese Yamato-e style which began in the twelfth century. More contemporary influences can be found in Paula Sedgwick's designs for chapter heads, which are reminiscent of Aubrey Beardsley's distinctive Art Nouveau style. One of the most important influences on American illustration is the immigration of artists from Europe who bring new inspiration from their own cultural heritage. Anatoly Ivanov's fantastic illustrations of folk tales find their roots deep in the past in the art of the Scythians, a migratory people of the Russian steppes. A field which encompasses comedy, drama, science, nature, fantasy, and realism has naturally resulted in a great diversity of approaches in style and medium.

The Rutgers Collection of Children's Literature provides an archive that can be utilized by a wide range of students and professionals. Illustration classes have frequently met at the art museum to study the work of established artists. Careful observation of the original art allows the student to learn from artists who have successfully experimented in a variety of media, styles, and techniques. The art museum has also organized exhibitions which will travel throughout the United States and Europe allowing the public access to this appealing artform. Since the expansion of the art museum, the collection has been on permanent display. The exhibit features a brief survey of the last fifty years of illustration, a didactic display which explains the process of creating a picture book, and the complete illustrations to one book which allows the public to see the illustrations as a complete work of art. The collection provides a wealth of material of great artistic appeal for the layman and the professional as well as a strong resource for scholars interested in the art of children's books. 